\title{
PURIFICAÇÃO DE GLICEROL OBTIDO NA PRODUÇÃO DE BIODIESEL
}

\author{
N. ASSIS ${ }^{1}$, I. S. T. PERASSI ${ }^{1}$, M. R. WOLF e F. A. V. PEREIRA ${ }^{1}$ \\ ${ }^{1}$ Pontifícia Universidade Católica do Paraná, Curso de Engenharia Química \\ E-mail para contato: nadine.assis@pucpr.edu.br
}

\begin{abstract}
RESUMO - Com a crescente produção de biodiesel, um volume muito grande de glicerina vem sendo gerado, produto este que pode ser aproveitado em muitos setores industriais, desde que possua um grau de pureza compatível com a empregabilidade. Sendo assim, rotas de baixo custo de purificação são de grande importância, pois além de conferirem maior valor agregando à glicerina, também viabilizam a produção do biocombustível. Este estudo apresenta um método de purificação alternativo para o glicerol produzido como coproduto da transesterificação de óleo de soja, tanto por rota metílica, quanto por rota etílica. $\mathrm{Na}$ metodologia empregada, a etapa de pré-purificação se dá através de uma acidificação seguida de neutralização e remoções de sais por adição de solvente polar (salting-out) enquanto que a purificação é realizada com carvão ativado. Além disso, um planejamento experimental também foi proposto numa tentativa de melhorar o grau de pureza do produto. Por isso, mudanças foram realizadas nas etapas de salting-out e de adsorção. As amostras obtidas foram caracterizadas quanto ao teor de glicerol, obtendo como melhor resultado um teor de $88,83 \% \pm$ 0,05 . As quantidades de sais removidos no salting-out também foram avaliadas, sendo que o melhor resultado foi para a maior proporção de álcool utilizada. Sendo assim, foi possível estabelecer um comparativo entre as amostras obtidas ao longo do processo de purificação.
\end{abstract}

\section{INTRODUÇÃO}

Segundo Costenaro (2009), no final da década de 1990, assim como outros países, o Brasil passou a investir fortemente em pesquisas para o desenvolvimento de biocombustíveis, principalmente o biodiesel. Combustível este, que é obtido através de uma reação denominada transesterificação, onde um triaglicerídeo reage com um álcool de cadeia curta na presença de um catalisador, produzindo assim, o alquil éster correspondente. Além do biodiesel, durante a reação, é produzido também cerca de $10 \%$ de glicerina bruta, oriunda do óleo utilizado (Knothe et al., 2006).

Com o advento do biodiesel, a partir dos anos 2000, o mercado da glicerina passou a ser ditado pela demanda do combustível, já que com o aumento da produção do biocombustível houve também um aumento no volume de glicerina. De acordo com a Agência Nacional do Petróleo, Gás Natural e Biocombustíveis (2015), só no Brasil, em 2014, foram gerados cerca de $311,8 \mathrm{mil} \mathrm{m}^{3}$ de glicerina bruta. 
Além disso, as indústrias que mais consomem o produto são a de fármacos, produtos de higiene pessoal e cosméticos, indústrias estas que necessitam de uma glicerina com alto grau de pureza. As indústrias de alimentos, têxtil, tabaco e de tintas e vernizes, também demandam uma grande quantidade de glicerol (Pinheiro et al., 2010).

Por isso, rotas de purificação baratas são de suma importância, já que o método de purificação dito convencional, que consiste na acidificação e neutralização da glicerina seguida de uma evaporação e posteriormente uma destilação à vácuo, branqueamento e desodorização com carvão ativado, é de alto consumo energético (Oppe, 2008).

Sendo assim, no presente estudo, realizou-se a purificação da glicerina através de uma na hidrólise ácida do material bruto, seguida de uma neutralização e remoção de sais solúveis através do efeito salting-out, uma evaporação e por fim, passagem do material evaporado por carvão ativado.

\section{MATERIAIS E MÉTODOS}

Para que o processo de purificação fosse eficiente, foi necessário que a glicerina bruta separada do biodiesel recebesse um tratamento prévio para a remoção de impurezas presentes, pois segundo Oppe (2012), poderia conter excesso de catalisador, sabões e também excesso do álcool utilizado na transesterificação.

Na hidrólise, ácido sulfúrico $(3,0 \mathrm{M})$ reagiu com os sabões presentes na mistura, formando ácidos graxos e o sal correspondente. Além desta reação, o ácido também foi responsável por transformar o glicerato de sódio contido na glicerina bruta em glicerol e sal. Para que esta fase fosse eficaz, a glicerina bruta foi aquecida até $60{ }^{\circ} \mathrm{C}$ e acidificada de forma que o pH final da mistura estivesse próximo de 4,0 (Lopes et al., 2014).

Depois da acidificação, a glicerina foi transferida para um funil de separação no qual ocorre a divisão em três fases: a mais densa, composta por sal, a intermediária rica em glicerol e a sobrenadante composta de ácidos graxos. A parte mais densa, constituída de glicerina e sal, foi separada dos ácidos graxos e centrifugada. Todavia, a glicerina ainda possuía $\mathrm{pH}$ baixo, portanto, foi neutralizada com $\mathrm{NaOH}$ (6,0 M) (Costenaro, 2009).

Na última etapa do processo de pré-purificação, correspondente ao denominado efeito salting-out ou precipitação por anti-solvente, etanol P.A. foi adicionado na proporção 2:1 em relação ao volume de glicerina, com o objetivo de modificar a solubilidade do soluto na solução original, fazendo com que o sal solúvel então precipitasse. Ao final do salting-out, o sal foi removido por centrifugação e o etanol por evaporação (Costenaro, 2009).

Quando a pré-purificação foi concluída, deu-se início a purificação da glicerina através da adsorção com carvão ativado (adsorvente). Segundo Souza (2013), a adsorção consiste num processo de remoção de impurezas, cor e odor, através de interações intermoleculares, onde o resíduo a ser removido interage com o carvão, que acaba retendo as impurezas em seus poros.

Após a reprodução da metodologia proposta por Lopes et al. (2014), um planejamento experimental foi proposto, para avaliar possíveis otimizações nas etapas de salting-out e de 
adsorção. Para isto, foi utilizada glicerina bruta oriunda da fabricação de biodiesel etílico produzido com óleo residual na planta piloto de biodiesel da PUCPR e também as glicerinas brutas geradas pelo grupo de pesquisa.

Um dos fatores avaliados, tratava da proporção de etanol utilizado na etapa de saltingout, com o objetivo de remover uma quantidade de sal maior da mistura neutralizada. Sendo assim, testes com proporções de álcool de 1:1, 2:1 e 2,5:1 em relação ao volume de glicerina, foram executados.

Além disso, mudanças na adsorção com carvão ativado também foram realizadas, por isso, a temperatura de adsorção, bem como a massa de carvão e o tempo de contato foram alterados, conforme apresenta a Tabela 1, de forma que a melhor combinação destas variáveis fosse encontrada, para um mesmo volume de $25 \mathrm{~mL}$ de glicerina pré-purificada.

Tabela 1 - Planejamento Experimental para Adsorção.

\begin{tabular}{ccc}
\hline Temperatura $\left({ }^{\circ} \mathbf{C}\right)$ & Massa de Carvão Ativado $(\mathbf{g})$ & Tempo de Contato $(\mathbf{h})$ \\
\hline \multirow{3}{*}{40} & 1,500 & 0,5 \\
\cline { 2 - 3 } & 2,500 & 0,5 \\
\cline { 2 - 3 } & 1,500 & 2,0 \\
\cline { 2 - 3 } & 2,500 & 2,0 \\
\hline 50 & 2,000 & 1,0 \\
\hline \multirow{3}{*}{60} & 1,500 & 0,5 \\
\cline { 2 - 3 } & 2,500 & 0,5 \\
\cline { 2 - 3 } & 1,500 & 2,0 \\
\cline { 2 - 3 } & 2,500 & 2,0 \\
\hline
\end{tabular}

Fonte: As autoras, 2016

Para caracterização das amostras quanto ao teor de glicerol, valeu-se do método do Periodato de Sódio.

\section{RESULTADOS E DISCUSSÕES}

\subsection{Caracterização da Glicerina Bruta}

Foram realizadas análises para determinação do teor de glicerol com a finalidade de comparar as amostras utilizadas. Na Tabela 2 a amostra 1 é a glicerina metílica, a amostra 2 tem origem de biodiesel via rota etílica e a amostra 3 é glicerina bruta proveniente da planta piloto.

Tabela 2 - Teor de Glicerol na Glicerina Bruta.

\begin{tabular}{cc}
\hline Amostra & Teor de Glicerol (\%) \\
\hline 1 & $34,386 \pm 0,579$ \\
\hline 2 & $13,381 \pm 1,689$ \\
\hline 3 & $12,447 \pm 0,784$ \\
\hline
\end{tabular}

Fonte: As autoras, 2016 
Como para o planejamento experimental optou-se por utilizar a glicerina bruta proveniente da unidade piloto, foi possível perceber que, apesar de possuir menos glicerol que as demais amostras, existe uma proximidade entre o teor de glicerol da glicerina da planta piloto e da glicerina etílica, já que ambas são produzidas pela mesma rota alcoólica, enquanto que a glicerina metílica apresenta um teor de glicerol mais elevado e compatível com os valores mencionados por Oppe (2012), que variam entre 30 e 60\%, para glicerinas brutas de mesma origem.

\subsection{Salting-out}

Para o a remoção de sal através do efeito salting-out, as diferentes proporções de álcool testadas são apresentadas na Tabela 3, juntamente com a porcentagem de sal removido e o teor de glicerol das amostras.

Tabela 3 - Remoção de Sal e Teor de Glicerol após Salting-out.

\begin{tabular}{ccc}
\hline Proporção de Etanol & Sal Removido (\%) & Teor de Glicerol (\%) \\
\hline $1: 1$ & $43,559 \pm 0,100$ & $72,590 \pm 1,647$ \\
\hline $2: 1$ & $52,604 \pm 0,472$ & $78,402 \pm 2,297$ \\
\hline $2,5: 1$ & $62,031 \pm 2,416$ & $85,533 \pm 0,144$ \\
\hline
\end{tabular}

Fonte: As autoras, 2016

É evidente que com a proporção de etanol de 2,5:1 em relação ao volume de glicerina, houve maior remoção de sais se comparada as proporções de 1:1 e 2:1. Além disso, nota-se que o teor de glicerol sofreu alteração, sendo melhorado à medida que a proporção de álcool aumentou.

\subsection{Adsorção}

Para os ensaios de adsorção, 9 amostras foram testadas e caracterizadas, sendo os resultados demonstrados de acordo com a temperatura de adsorção. A glicerina utilizada nestes testes, foi pré-purificada utilizando a proporção de álcool de 2,5:1 em relação ao volume de glicerina, obtendo ao final da evaporação, um material com 85,533\% $\pm 0,144$ de glicerol.

Para a temperatura de $40{ }^{\circ} \mathrm{C}$, os teores de glicerol para os testes, são demonstrados na Tabela 4.

Tabela 4 - Teor de Glicerol após Adsorção à $40^{\circ} \mathrm{C}$.

\begin{tabular}{ccc}
\hline Massa de Carvão (g) & Tempo de Contato (h) & Teor de Glicerol (\%) \\
\hline 1,500 & 0,5 & $79,928 \pm 0,951$ \\
\hline 2,501 & 0,5 & $85,533 \pm 1,267$ \\
\hline 1,501 & 2,0 & $87,111 \pm 0,871$ \\
\hline 2,500 & 2,0 & $83,412 \pm 3,110$ \\
\hline
\end{tabular}

Fonte: As autoras, 2016 
Para a temperatura de $50{ }^{\circ} \mathrm{C}$, foram utilizados $2,000 \mathrm{~g}$ de carvão ativado e o tempo de contato foi de $1,0 \mathrm{~h}$. Para este ensaio, o teor de glicerol foi de $(88,829 \% \pm 0,050)$. Já para $60{ }^{\circ} \mathrm{C}$, os dados foram dispostos na Tabela 5 .

Tabela 5 - Teor de Glicerol após Adsorção à $60^{\circ} \mathrm{C}$.

\begin{tabular}{ccc}
\hline Massa de Carvão (g) & Tempo de Contato (h) & Teor de Glicerol (\%) \\
\hline 1,500 & 0,5 & $79,549 \pm 1,331$ \\
\hline 2,502 & 0,5 & $79,398 \pm 0,354$ \\
\hline 1,501 & 2,0 & $85,784 \pm 1,519$ \\
\hline 2,501 & 2,0 & $82,337 \pm 0,779$ \\
\hline
\end{tabular}

Fonte: As autoras, 2016

Apesar das mudanças propostas, nota-se que o maior teor de glicerol foi verificado para o ponto central do planejamento experimental, ou seja, para os parâmetros indicados na metodologia empregada. No entanto, os valores encontrados são bastante próximos e, se comparados ao teor inicial da glicerina bruta utilizada, deixam evidente a melhora na pureza do material.

Além disso, algumas das amostras caracterizadas poderiam ser classificadas como glicerina loira, já que segundo Mota et al., (2009), para ser identificada como loira, a glicerina precisa conter cerca de $80 \%$ de glicerol. Sendo assim, podem ser empregadas como aditivos em tintas, vernizes, rações animais e também como plastificantes (Lopes et al., 2014)

\section{CONCLUSÃO}

Devido à grande quantidade de setores industriais que utilizam glicerina como matériaprima e pela necessidade de um produto com alto grau de pureza, rotas com menor custo de purificação são tão importantes e necessárias, pois, além de conferirem maior valor agregado ao glicerol viabilizam também a produção do biodiesel, já que atualmente, a fabricação do biocombustível é responsável por gerar grandes volumes de glicerina bruta.

Com o estudo, verificou-se a obtenção da glicerina loira, material este que pode ser empregado na fabricação de tintas e vernizes, rações animais e também como plastificantes, conferindo mais resistência e flexibilidade aos plásticos.

Por isto, métodos com uma rota alternativa de purificação foram avaliados e então melhorias foram propostas, para maximizar o teor de glicerol no produto final e reduzir os custos com purificação. Na primeira alteração sugerida, avaliou-se a proporção de etanol e os resultados mais satisfatórios foram para a proporção de 2,5:1, já que os teores de glicerol demonstraram melhorias à medida que a quantidade de álcool foi aumentada.

$\mathrm{Na}$ adsorção, o melhor resultado foi observado no ponto central do experimento, aumentado o teor do glicerol em mais de $70 \%$, quando comparado à glicerina bruta. Mas, apesar dos resultados aceitáveis, ainda existem oportunidades para melhorias no procedimento empregado. No entanto, um destino correto já poderia ser dado à glicerina obtida no estudo, visto que atende a necessidade de alguns setores industriais. 


\section{REFERÊNCIAS}

AGÊNCIA NACIONAL DE PETRÓLEO, GÁS NATURAL E BIOCOMBUSTÍVEIS. Anuário estatístico brasileiro de petróleo, gás natural e biocombustíveis. 2015. Disponível em: <http://www.anp.gov.br/?id=661>. Acesso em 26 jul. 2016.

COSTENARO, H. S. Hidrólise Ácida e Retirada de Sais da Glicerina Bruta Proveniente da Produção de Biodiesel. 2009. 136f. Dissertação (Mestrado em Engenharia Química) Universidade de São Paulo, São Paulo, 2009.

KNOTHE, G; KRAHL, J.; GERDEN, J. V.; RAMOS, L. P. Manual de biodiesel. São Paulo: Edgard Blücher, 2006.

LOPES, A. P.; CANESIN, E. A.; SUZUKI, R. M.; TONIN, L. T. D.; PALIOTO, G. F.; SAIXAS, F. L. Purificação de Glicerina Residual Obtida na Produção de Biodiesel a partir de Óleos Residuais. Revista Virtual de Química. v. 6, n. 6, 1564 - 1582, 2014. Disponível em: <http://www.uff.br/RVQ/index.php/rvq/article/download/761/520>. Acesso em: 3 set. 2015.

MOTA, C. J. A.; SILVA, C. X. A.; GONÇALVES, V. L. C. Gliceroquímica: novos produtos e processos a partir da glicerina de produção de biodiesel. Química Nova. v. 32, n.3, 639 - 648, 2009. Disponível em: <http://www.scielo.br/pdf/qn/v32n3/a08v32n3.pdf>. Acesso em: 1 set. 2015.

OPPE, E. Desidratação por destilação azeotrópica da glicerina obtida como subprodutos da produção de biodiesel. 2012. 127f. Dissertação (Mestrado em Engenharia Química) Universidade de São Paulo, São Paulo, 2008.

OPPE, E. Estudo da desidratação do glicerol por destilação trifásica em colune de pratos perfurados. 2012. 126f. Dissertação (Doutorado em Engenharia Química) Universidade de São Paulo, São Paulo, 2012.

PINHEIRO, R. S.; CÉSAR, A. S.; BATALHA, M. O. Impacto da produção de glicerina derivada de biodiesel em outros setores: um estudo multi-caso. XXX Encontro Nacional de Engenharia de Produção. 2010. Disponível em: <http://www.abepro.org.br/biblioteca/enegep2010_TN_STO_113_741_16034.pdf>. Acesso em 26 de jul. 2016.

SOUZA, F. Purificação da glicerina obtida como coproduto na produção de biodiesel com óleo de soja refinado. 2013. 58f. Trabalho de Conclusão de Curso (Tecnólogo em Processos Ambientais) - Universidade Tecnológica Federal do Paraná, Curitiba, 2013. 